\title{
Sensitive routine liquid chromatography-tandem mass spectrometry method for serum estradiol and estrone without derivatization
}

Steven Pauwels ${ }^{1,2 *}$, Leen Antonio ${ }^{3,4 *}$, Ivo Jans ${ }^{1}$, Anneleen Lintermans ${ }^{5}$, Patrick Neven ${ }^{5,6,7}$, Frank Claessens $^{4}$, Brigitte Decallonne ${ }^{3}$, Jaak Billen ${ }^{1}$, Dirk Vanderschueren ${ }^{1,3 \circ}$ and Pieter Vermeersch ${ }^{1,2 \circ}$

*Steven Pauwels and Leen Antonio contributed equally to this work.

${ }^{\circ}$ Dirk Vanderschueren and Pieter Vermeersch contributed equally to this work.

1. Clinical Department of Laboratory Medicine, University Hospitals Leuven, Leuven, Belgium

2. Department of Cardiovascular Sciences, KU Leuven, Leuven, Belgium

3. Laboratory of Clinical and Experimental Endocrinology, Department of Clinical and Experimental Medicine, KU Leuven, Leuven, Belgium

4. Laboratory of Molecular Endocrinology, Department of Cellular and Molecular Medicine, KU Leuven, Leuven, Belgium

5. Department of Oncology, KU Leuven, Leuven, Belgium

6. Multidisciplinary Breast Center, University Hospitals Leuven, Leuven, Belgium

7. Clinical Department of Gynecology and Obstetrics, University Hospitals Leuven, Leuven, Belgium

Corresponding author:

Steven Pauwels, University Hospitals Leuven, Laboratory Medicine, Herestraat 49, 3000 Leuven, Belgium, tel. +3216 3413 90, fax.+3216 3470 42, email: steven.pauwels@uzleuven.be

Key Words: Estradiol, Estrone, Mass Spectrometry, Liquid Chromatography, MRM summation

Conflicts of interest: All authors, no conflict

Abbreviations: Al, aromatase inhibitors; LC-MS/MS, liquid chromatography-tandem mass spectrometry; E2, 17 $\beta$ estradiol; E1, estrone; IS, internal standard; IS2, 17ß-estradiol-16,16,17-d3; IS1, estrone-2,3,4-13C; BSA, bovine serum albumin; LC-MS, liquid chromatography-mass spectrometry; CRM, certified reference material; $Q C$, quality control; 2D, 2 dimensional; ESI, electrospray ionization; MRM, multiple reaction monitoring; LOQ, limit of quantification; S/N, signal-to-noise ratio; CV, coefficient of variation; ME, matrix effect; MS, mass spectrometry; ECLIA, electrochemiluminescence immunoassay; RIA, radio-immunoassay; $\mathrm{Cl}$, control intervalconfidence interval 


\section{Abstract}

The need for a routinely applicable assay to measure low estradiol levels in adult men, postmenopausal women, and young adolescents was recently discussed in an Endocrine Society position statement. Our aim was to develop a sensitive liquid chromatography-tandem mass spectrometry method for estradiol and estrone in human serum without the need for derivatization or extended extraction protocols.

After protein precipitation of serum with a mixture of methanol/acetonitrile (85/15) $(\mathrm{v} / \mathrm{v})$ containing isotopic internal standards (17ß-estradiol-16,16,17-d3 and estrone-2,3,4-13C), we quantified estradiol and estrone by two-dimensional liquid chromatography-tandem mass spectrometry with electrospray ionization in the negative mode monitoring $5 \times 271.20 .145 .00$ (17ß-estradiol) and 269.20.145.00 (estrone). Sensitivity was increased by using fluoride and summation of 5 identical transitions for estradiol. Our method was analytically validated, compared against direct immunoassays using serum of 25 adult men, and clinically tested by measuring samples of 3 men at baseline and after chemical castration, 30 postmenopausal women and 15 patients receiving aromatase inhibitors.

Total imprecision was below $20 \%$ for the low quality controls. Limit of quantification was $1.3 \mathrm{ng} / \mathrm{L}$ (4.8 $\mathrm{pmol} / \mathrm{L}$ ) for estradiol and $1.2 \mathrm{ng} / \mathrm{L}(4.4 \mathrm{pmol} / \mathrm{L})$ for estrone. Estradiol in Certified Reference Material BCR-576 was within specified uncertainty limits. No significant ion suppression or interference was observed. Our method showed modest correlation with direct immunoassay for estradiol $\left(r^{2}=0.64\right)$ but no correlation for estrone $\left(r^{2}=0.12\right)$. Patient sample results were within expected ranges.

In conclusion, we developed a routinely applicable liquid chromatography-tandem mass spectrometry method for estradiol and estrone measurement which is sensitive enough for use in men, postmenopausal women, and young adolescents. 


\section{Introduction}

Estrogens are crucial for female reproduction and are involved in the pathophysiology of malignancies such as breast cancer. Moreover, estrogens are also essential for bone health, pubertal development, and growth, both in women and men (Callewaert et al. 2010). Direct immunoassays are the most widely used techniques for measuring serum estradiol in research and clinical laboratories. Unfortunately, commercially available immunoassays for estradiol lack precision and accuracy in the low range (<20 ng/L) (<73.5 pmol/L) and are susceptible to interference (Middle et al. 2009, Blair 2010, Stanczyk et al. 2010, Fiers et al. 2012, Jaque et al. 2013, Rosner et al. 2013). The same problem has been described for estrone (Fiers et al. 2012).

A recent position statement from the Endocrine Society discussed the need for a routinely applicable assay to reliably measure low estradiol concentrations in adult men, postmenopausal women, and young adolescents (Rosner et al. 2013). Moreover, assays should be able to distinguish between pretreatment levels and suppressed levels $(1 \mathrm{ng} / \mathrm{L})(3.7 \mathrm{pmol} / \mathrm{L})$ for postmenopausal breast cancer patients treated with aromatase inhibitors (AI) (Pauwels et al. 2013, Rosner et al. 2013).

Mass spectrometry can overcome the above-mentioned limitations of immunoassays and is therefore presently the method of choice for estrogen measurement. However, all reported methods to date rely on derivatization and/or extended extraction protocols to obtain sufficient sensitivity (Nelson et al. 2004, Tai et al. 2005, Xu et al. 2007, Yamashita et al. 2007, Kushnir et al. 2008, Yang et al. 2008, Fiers et al. 2012, Ray et al. 2012, Ronan et al. 2013). Moreover, larger sample volumes (up to $5 \mathrm{~mL}$ (Tai et al. 2005)) and long run times (up to $70 \mathrm{~min}$ (Xu et al. 2007)) can further hamper the use of some of these methods in routine practice. Our aim was to develop a routinely applicable, sensitive liquid chromatography-tandem mass spectrometry (LC-MS/MS) method for the quantification of low concentrations of estradiol and estrone in human serum by using a simple sample pretreatment protocol without derivatization.

\section{Materials and Methods}

\section{Reagents}

17ß-Estradiol (E2) and estrone (E1) were obtained from Sigma-Aldrich. As internal standard (IS), 17ßestradiol16,16,17- d3 (IS2) (isotopic purity $98 \%$ ) was purchased from Medical Isotopes and estrone2,3,4-13C (IS1) (isotopic purity $99 \%$ ) from Sigma-Aldrich. Bovine serum albumin (BSA), $100 \%$ free from E2 and E1, was purchased from Sigma- Aldrich (product number A7030). Ethanol and 2-propanol were analytical grade and obtained from VWR. Liquid chromatography- mass spectrometry (LC-MS)-grade water was generated using a Milli-Q-water-purification system (Millipore). Acetonitrile (LC-MS grade) was purchased from Biosolve, Optima ${ }^{\circledR}$ LC-MS Methanol from Fisher Scientific and ammonium fluoride 
(LC-MS eluent additive grade) from Fluka. Certified reference material (CRM) BCR-576 was obtained from the Institute for Reference Materials and Measurements (Joint Research Centre, European Commission), Geel, Belgium.

Leftover serum from routine samples of 1 -year-old boys was used as blank serum. Standard stock solutions were prepared in ethanol at $1.1 \mathrm{~g} / \mathrm{L}(4 \mu \mathrm{mol} / \mathrm{L})$ for E2 and at $0.6 \mathrm{~g} / \mathrm{L}(2.2 \mu \mathrm{mol} / \mathrm{L})$ for E1. IS stock solutions were prepared in 2-propanol at $1.0 \mathrm{~g} / \mathrm{L}(3.6 \mu \mathrm{mol} / \mathrm{L}$ IS2 and $3.7 \mu \mathrm{mol} / \mathrm{L} \mathrm{IS} 1)$. Calibration standards were prepared at 1.3 (4.8), 2.7 (9.9), 5.4 (19.8), 26.8 (98.5) and $53.5 \mathrm{ng} / \mathrm{L}(196.7 \mathrm{pmol} / \mathrm{L})$ for E2 and 1.2 (4.4), 2.5 (9.3), 4.9 (18.1), 19.6 (72.6), 39.2 (145.1), 78.4 (290.4) and 156.8 ng/L (580.8 $\mathrm{pmol} / \mathrm{L}$ ) for E1 by spiking dilutions of the respective standard stock solutions in surrogate matrix containing BSA (60 g/L in saline) with addition of $2 \%$ blank serum. Quality control (QC) samples were prepared by pooling serum leftovers from adult males from routine analyses at $22.5 \mathrm{ng} / \mathrm{L}(82.7 \mathrm{pmol} / \mathrm{L})$ for E2 and $30.0 \mathrm{ng} / \mathrm{L}$ (111.1 pmol/L) for E1. These high level QC samples were further diluted with leftover serum from 1-to 9-year-old boys to prepare low level QC samples at $1.5 \mathrm{ng} / \mathrm{L}$ (5.5 pmol/L) for E2 and $3.0 \mathrm{ng} / \mathrm{L}(11.1 \mathrm{pmol} / \mathrm{L})$ for E1.

\section{Sample pretreatment}

Three hundred microliters of calibration standard, QC or patient serum was pipetted into glass tubes. Subsequently, $600 \mu \mathrm{L}$ of a methanol/acetonitrile mixture (85/15) (v/v) containing IS2 at $30 \mathrm{ng} / \mathrm{L}$ (109.1 $\mathrm{pmol} / \mathrm{L})$ and IS1 at $10 \mathrm{ng} / \mathrm{L}(36.6 \mathrm{pmol} / \mathrm{L})$ was added to each tube. The mixture was vortexed three times for $5 \mathrm{~s}$ at regular intervals during incubation at room temperature for at least $1 \mathrm{~h}$. After incubation, the mixture was centrifuged at $2-8{ }^{\circ} \mathrm{C}$ for $10 \mathrm{~min}$ at $1,800 \times \mathrm{g}$. The supernatant was then transferred into borosilicate glass tubes. The tubes were heated in a hot water bath at $95^{\circ} \mathrm{C}$ during 3 min. The remaining supernatant was transferred without centrifugation into a deep well plate (Captiva 96well 1-mL collection plate, Agilent Technologies) and placed in the autosampler, ready for injection.

\section{LC-MS/MS conditions}

The LC-MS/MS analysis was performed on an AB/Sciex QTrap 5500 tandem mass spectrometer with a Turbo $V^{\mathrm{TM}}$ ion source combined with a 2 dimensional (2D) chromatography system, consisting of 4 Shimadzu LC-20 AD pumps, a CTO-20 AC column oven, a CBM-20A controller, a SIL20 AC autosampler and a Rheodyne 10 port 2 position valve. We used a Poros R1/10 $(4.6 \times 50 \mathrm{~mm})$ (Applied Biosystems) column for the first dimension and an Onyx Monolythic C18 $(3 \times 100 \mathrm{~mm})$ (Phenomenex) for the second dimension. We operated the mass spectrometer in electrospray ionization (ESI) negative ion mode with ion spray voltage set to $-4500 \mathrm{~V}$ and Turbo Ion Spray Source temperature at $550^{\circ} \mathrm{C}$. Declustering potential was set at $-150 \mathrm{~V}$ and entrance potential at $-7 \mathrm{~V}$. Curtain gas was $241 \mathrm{kPa}$ (35 psi). Unit 
resolution was used in both Q1 and Q3. The multiple reaction monitoring (MRM) transitions and MS settings are described in 0 . Oven temperature was $30^{\circ} \mathrm{C}$ for the first dimension and room temperature for the second dimension (analytical column). At 0 min $200 \mu \mathrm{L}$ of supernatant was injected into the first chromatographic dimension. The switch valve was in default position (0) from 0.00 to $3.02 \mathrm{~min}$, disconnecting both dimensions. During this time, analyte molecules were enriched on the Poros column and possible interferents were eluted to the waste by applying a linear gradient from $70 \%$ water (solvent A) and $30 \%$ methanol/acetonitrile mixture (75/25) (v/v) (solvent B) to $59 \%$ solvent A and $41 \%$ solvent B from 0.00 to $1.62 \mathrm{~min}$ and from $1.62 \mathrm{~min}$ on $81 \%$ solvent B up to $4.47 \mathrm{~min}$. Meanwhile, the analytical column was equilibrated with $100 \% 0.4 \mathrm{mmol} / \mathrm{L}$ ammonium fluoride in water (solvent C) at $0.50 \mathrm{~mL} / \mathrm{min}$. From $3.02-4.49 \mathrm{~min}$ the switch valve was set in position 1 , connecting the Poros and the analytical column in series at a combined flow rate of $0.61 \mathrm{~mL} / \mathrm{min} \quad(0.25$ $\mathrm{mL} / \mathrm{min}$ on Poros added to $0.36 \mathrm{~mL} / \mathrm{min}$ on the analytical column). Analytes eluted from the Poros to the analytical column during this time frame. At $4.49 \mathrm{~min}$ the switch valve was reset to the default position. From 4.56 to $7.52 \mathrm{~min}$ a very slow linear gradient at $0.50 \mathrm{~mL} / \mathrm{min}$ was applied on the analytical column, ranging from $35 \%$ solvent $C$ and $65 \%$ methanol (solvent D) at time 4.56 to $31 \%$ solvent $C$ and $69 \%$ solvent $D$ at time 7.52 . From 7.52 to $12.01 \mathrm{~min}$ both dimensions were prepared to initial conditions for the next injection. Details on gradients, valve switching and flow are described in Supplementary Table 1.

\section{LC-MS/MS data analysis}

We used Analyst 1.5.1 ( $\mathrm{AB} / \mathrm{Sciex}$ ) to integrate selected peaks. Quantification was performed with the peak area count ratio of E1 to IS1 and E2 to IS2. For the E2 peak area count, all five identical MRMs were summated using the Sum Multiple lon feature of the software. We plotted area count ratios of the calibrator standards and applied an unweighted linear regression to obtain calibration curves.

\section{Assay performance characteristics}

Imprecision, limit of quantification, linearity, and carryover

Method imprecision was evaluated by analyzing in duplo 2 runs of QC samples on ten consecutive days at two levels (CLSI 2004). Limit of quantification (LOQ) was defined as the lowest concentration with a signal-to-noise ratio $(\mathrm{S} / \mathrm{N}$ ) of more than 10 and a coefficient of variation (CV) of less than $20 \%$ (CLSI 2007). The LOQ was determined by analyzing calibration standards during ten consecutive days. The $\mathrm{CV}$ of the area count ratio was calculated as well as $\mathrm{S} / \mathrm{N}$. Linearity was evaluated by calculation of the 
coefficient of determination ( $r 2$ ) for calibration curves of E2 and E1. Carryover was evaluated by analyzing two blanks (water) after the highest calibration standards of E2 and E1.

\section{Accuracy}

We tested the accuracy of the method for E2 through analysis of CRM BCR-576 in 5 different runs. The different runs were performed within $8 \mathrm{~h}$ after reconstitution in accordance with the instructions for use. To the best of our knowledge, no such reference serum exists for E1.

Ion suppression, matrix effect, and interference

Ion suppression was examined by a post-column infusion experiment (Annesley 2003). E2 at $1 \mu \mathrm{g} / \mathrm{L}$ $(3.6 \mu \mathrm{mol} / \mathrm{L})$ and $\mathrm{E} 1$ at $0.5 \mu \mathrm{g} / \mathrm{L}(1.9 \mu \mathrm{mol} / \mathrm{L})$, both dissolved in ethanol, were infused into the mass spectrometer at $10 \mu \mathrm{L} / \mathrm{min}$ during the chromatographic analysis of 3 different blank serum extracts of 1-year-old boys. We determined the effect of sample matrix by comparing the area count ratios for calibrators, spiked blank serum and spiked neat solutions in methanol (matrix free). The sample matrix effect $(M E)$ was calculated with the equation $M E \%=B / A \times 100$, where $B$ refers to the area count ratios of E2 or E1 to IS obtained from samples in matrix and A to the area count ratios in matrix free samples (Botelho et al. 2013). Interference by other endogenous compounds was tested by analyzing three different blank leftover serum samples of 1-year-old boys and CRM BCR-576, which is lyophilized human serum, containing all expected and possibly interfering endogenous compounds. Interference was defined as an unexpected peak at the retention time of E2 or E1.

\section{Method comparison with direct immunoassay}

Leftover serum of 25 adult males (aged 33-87 years) was analyzed by mass spectrometry (MS), routine direct immunoassay for E2 (electrochemiluminescence estradiol assay on Modular E170 from Roche Diagnostics) (ECLIA) and direct radio-immunoassay (RIA) (Diagnostics Systems Laboratories Inc.) for E1. Passing-Bablok non parametric regression, Deming regression and the coefficient of determination (r2) were used to study correlation and interchangeability between results (Passing et al. 1983). Data analysis was performed using Microsoft Excel Analyze-it version 2.21 (Analyse-it Software Ltd).

\section{Patient samples}

E2 and E1 were measured by MS in serum of men $(n=3)$ at baseline and after chemical castration by the antiandrogen cyproterone acetate, postmenopausal women $(n=30)$ (aged 53-88 years) and 15 breast cancer patients, treated with $\mathrm{Al}(\mathrm{n}=15)$ ( 5 with anastrozole, 5 with letrozole and 5 with exemestane). All patients gave written informed consent and the study protocols were approved by our institutional review board. 


\section{Results}

Chromatograms of E2 and IS2, and E1 and IS1 are shown in 0. Our approach to sum 5 identical MRM transitions for E2 increased the signal four-fold and S/N 1.5-fold (0).

Total imprecision was less than $20 \%$ for the low QC sample and below $10 \%$ for the high QC (0). The LOQ was set at $1.3 \mathrm{ng} / \mathrm{L}(4.8 \mathrm{pmol} / \mathrm{L})$ for $\mathrm{E} 2$ as the $\mathrm{CV}$ at this level was only $12.4 \%$ and $\mathrm{S} / \mathrm{N}$ was 12 . The LOQ for E1 was at least $1.2 \mathrm{ng} / \mathrm{L}(4.4 \mathrm{pmol} / \mathrm{L})$. The $\mathrm{CV}$ at this level was $4.7 \%$ and $\mathrm{S} / \mathrm{N} 15$. Since the lowest calibration standards only had an $\mathrm{S} / \mathrm{N}=15$, no further dilutions were made. The assay was linear from 1.3 (4.8) to $53.5 \mathrm{ng} / \mathrm{L}(196.7 \mathrm{pmol} / \mathrm{L})$ for E2 ( $\mathrm{r} 2>0.999)$ and from 1.2 (4.4) to $156.8 \mathrm{ng} / \mathrm{L}$ (580.8 $\mathrm{pmol} / \mathrm{L})$ for $\mathrm{E} 1$ ( $\mathrm{r} 2>0.999)$. No significant carryover was detected $(<0.5 \%)$.

The average value for BCR-576 (32.21 ng/L (118.4 pmol/L)) was within the uncertainty limits specified on the certificate of analysis (114 $\pm 5 \mathrm{pmol} / \mathrm{L}$ which is equivalent to $31.05 \pm 1.36 \mathrm{ng} / \mathrm{L})$. The average value for E1 in BCR-576 was $40.47 \mathrm{ng} / \mathrm{L}$ (149.9 pmol/L).

Significant suppression of ionization was noticed in the chromatograms of E2 and E1 around 6.00 and $9.00 \mathrm{~min}$. No ion suppression was present at the retention time of E2 and E1. The percentage ME ranged from $85-120 \%$ at different concentrations for calibration standards and spiked blank serum (Supplementary Table 2). No interfering peaks were observed during the analyses of blank sera and BCR-576. Furthermore, up till now more than 300 samples have been analyzed and no interfering peaks or clinically unexpected levels of E2 or E1 have been identified.

We compared E2 and E1 as measured by MS and direct immunoassay in 25 adult males. The correlation was modest for E2 and ECLIA ( $r 2=0.67)$. For E1 and direct RIA no correlation was found ( $r 2=0.12$ ). Passing-Bablok regression (measurements in nanogram per liter) showed the equations E2 MS $=0.78$ $\times E 2$ ECLIA +2.79 , with $95 \%$ confidence interval (CI) of 0.55-1.00 on the slope and $-1.80-7.68$ on the intercept and E1 MS $=0.24 \times \mathrm{E} 1 \mathrm{RIA}+7.00$, with a $95 \% \mathrm{Cl}$ on the slope of 0.13-0.53 and on the intercept of -7.51-13.14. For both regressions a large scatter of the data points was present (0). Further results of the regression analyses are shown in Supplementary Table 3.

Results of the analyses of patient samples are summarized in Table 3 and Supplementary Table 4 (castrated men). In men, chemical castration lowered estrogen levels, but E2 was more suppressed than E1. Baseline levels were comparable to the values encountered during our method comparison for adult males and in accordance with literature (8-42 ng/L (Kushnir et al. 2008) and 10-40 ng/L (Mayo Clinic 2013) for E2;9-36 ng/L (Kushnir et al. 2008) and 10-60 ng/L (Mayo Clinic 2013) for E1). The median value for postmenopausal women was $3.2 \mathrm{ng} / \mathrm{L}$ (11.8 pmol/L) for E2 and $18.2 \mathrm{ng} / \mathrm{L}$ (67.4 $\mathrm{pmol} / \mathrm{L}$ ) for E1. The median and range were comparable to other published values for E2 and E1 in postmenopausal women, which were also determined by sensitive LC-MS/MS (2-21 ng/L (Kushnir et al. 2008) and <10ng/L (Mayo Clinic 2013) for E2;3- 32 ng/L (Kushnir et al. 2008) and 7-40 ng/L (Mayo 
Clinic 2013) for E1). Finally, samples from postmenopausal women receiving an Al as adjuvant endocrine therapy for breast cancer ( $n=5$ for each Al) were measured. As expected, E2 and E1 were close to or below LOQ in patients treated with the different Als (Folkerd et al. 2012, Pauwels et al. 2013, Rosner et al. 2013). During our clinical validation, we noticed that, for patients treated with exemestane, E2 values measured by MS were much lower than values measured by ECLIA (Supplementary Table 5). Patients treated with anastrozole or letrozole, in contrast, almost all had E2 values below LOQ (measuring range $5.0-4300.0 \mathrm{ng} / \mathrm{L}$ ) for ECLIA (8 out of 10). Two patients, one receiving anastrozole and the other letrozole, showed E2 values of $11.5 \mathrm{ng} / \mathrm{L}(42.3 \mathrm{pmol} / \mathrm{L})$ and 10.5 (38.6 pmol/L), respectively.

\subsection{Discussion}

We developed a sensitive LC-MS/MS method for E2 and E1 quantification that does not rely on extended extraction protocols or derivatization to obtain sufficient sensitivity for the measurement of estrogens in men, postmenopausal women or young adolescents. Furthermore, our method requires an acceptable low volume of serum and shows a relatively short run time. Our method is therefore suitable for routine use in the whole spectrum of patients without restriction to premenopausal women with higher serum estrogen levels.

One of the major problems of mass spectrometric analysis of steroids thus far is the difficult ionization due to their low polarity. It is known that ionic eluent compounds can form charged adducts with neutral molecules. If that adduct is stable, it can be measured instead of the mother molecule. This is particularly useful in molecules that are difficult to ionize (Sheen et al. 2004).

Fluoride has been shown to yield high abundant anionic adducts with different steroids, including E2. It has, however, been shown beneficial not to measure the anionic adduct itself, but to use a two-step approach. Following reaction of neutral E2 with fluoride, the anionic adduct is decomposed into hydrogen fluoride and the deprotonized precursor ion (Fiers et al. 2012, Rannulu et al. 2012). For estrogens, ionization improvement up to $80 \%$ for E2 and $35 \%$ for E1 has been described using this approach under optimized conditions and fluoride concentrations (Fiers et al. 2012). The final impact of this procedure on $\mathrm{S} / \mathrm{N}$ was however not reported.

The summation of different MRMs to increase sensitivity is also gaining popularity in LC-MS/MS methods (Manjunath Swamy et al. 2010). This approach requires more than one product ion of good quality. Our experiments showed that there was no such product ion for E2. Therefore, a novel approach to further increase sensitivity for E2 was used in this study. We summed five identical MRM transitions for E2. We found that the increase in peak signal is greater than the increase in random noise around the analyte peak. Contrary to the analyte peaks, which are occurring at the same time in 
the different identical MRMs, the noise peaks of different MRM spectra are mostly not overlaying due to their random character. Summation of MRMs will therefore result in a relative increase in $\mathrm{S} / \mathrm{N}$. Using this approach we achieved a four-fold (300 \%) increase of signal and 1.5-fold (50\%) increase of S/N for E2. Theoretically, this approach can be extended to a summation of even more identical MRMs to further increase sensitivity. The only limiting factors are the performance characteristics of the mass spectrometer and the software possibilities. Summation of many MRMs will therefore lead to a significant increase of the cycle time for an identical dwell time and hence a decrease in data points. Too little data points result in insufficient resolution. Our summation approach can theoretically be used for every molecule analyzed by LC-MS/MS. This may also open a new perspective for other analytes.

The comparison of our MS method with ECLIA in adult men showed only a modest correlation for E2 $\left(r^{2}=0.64\right)$. The slopes of the regression analyses indicated overestimation by ECLIA. The large confidence intervals also pointed to a large scattering of the data points. This is in line with previous comparisons showing reduced performance of ECLIA below $100 \mathrm{ng} / \mathrm{L}$ (370 pmol/L), which becomes problematic for concentrations below $20 \mathrm{ng} / \mathrm{L}$ (73.5 pmol/L) (Fiers et al. 2012). For E1, the correlation between mass spectrometry and direct RIA $\left(r^{2}=0.12\right)$ was even completely absent. The values obtained by direct RIA measurements were on average about threefold higher than our MS determinations with equal high scattering of data points.

Results of our MS method for adult men, postmenopausal women as well as patients treated with $\mathrm{Al}$, are in line with those reported in literature (Kushnir et al. 2008, Folkerd et al. 2012, Mayo Clinic 2013, Pauwels et al. 2013). The higher values in adult men measured by direct immunoassay are probably due to cross reactivity. Based on our results, the clinical utility of the tested direct RIA assay for low E1 must be questioned, further supporting the need for a sensitive, routine MS method.

During our clinical validation we also noticed that in patients treated with exemestane, E2 levels were much higher when measured by ECLIA compared to E2 levels determined by MS. To our knowledge, this interference with ECLIA has not been published previously and may be of clinical relevance. The cause of this overestimation has not been examined in detail, but is most likely related to cross reactivity with exemestane, which is steroidal, or its metabolites. Letrozole and anastrozole, in contrast, are non-steroidal.

Our new MS method also enables us to measure a difference in estrogen values between men at baseline and after chemical castration. This effect was more pronounced for E2, because castration by cyproterone acetate leads to lower testosterone levels, which are converted into E2 (but not E1) by the enzyme aromatase. To the best of our knowledge, this is the first demonstration that chemical castration reduces E2 levels well below the threshold level of $31 \mathrm{ng} / \mathrm{L}(114 \mathrm{pmol} / \mathrm{L})$ needed for skeletal sufficiency in elderly men (Khosla et al. 2002). This finding is important for patients receiving androgen 
deprivation therapy for prostate cancer, because this treatment is associated with an increased risk of osteoporotic fractures (Shahinian et al. 2005). As discussed by Rosner et al., reliable measurements of estradiol levels are important in assessing the metabolic effects of androgen deprivation in men (Rosner et al. 2013).

As expected, concentrations of E2, as well as E1, in postmenopausal women treated with an Al for breast cancer were also clearly lower than the levels for non-treated postmenopausal women (Folkerd et al. 2012).

The simplicity of our method allows application in routine settings that require accurate quantification of low concentrations of E2 and E1. The indications have recently been stated by the Endocrine Society and include adult males, postmenopausal women and young adolescents (Rosner et al. 2013). Moreover, assays should be able to distinguish between pretreatment levels and suppressed levels of E2 ( $<1 \mathrm{ng} / \mathrm{L}$ or below) for postmenopausal breast cancer patients receiving Als. More recent direct immunoassays for E2 with LOQs typically around $10 \mathrm{ng} / \mathrm{L}(36.8 \mathrm{pmol} / \mathrm{L})$ are not sensitive enough for this indication and are, as stated above, susceptible to interferences. Direct immunoassays are to be used mainly for women to diagnose and manage infertility and some other rare pathologies with rather high E2 or E1 levels (Rosner et al. 2013). Our LOQ of $1.3 \mathrm{ng} / \mathrm{L}$ (4.8 pmol/L) for E2 is at the cutoff suggested by the Endocrine Society. Further quantification below $1 \mathrm{ng} / \mathrm{L}(3.7 \mathrm{pmol} / \mathrm{L})$ E2 remains actually of unknown significance (Rosner et al. 2013).

In conclusion, we developed a sensitive LC-MS/MS method which is sensitive enough to measure E2 and E1 in men, postmenopausal women and young adolescents. Our method is the first one that does not require extensive sample pretreatment or derivatization, making it ideal for routine use in clinical practice. We succeeded in increasing sensitivity by combining 2D chromatography, fluoride, and the summation of identical MRMs.

\section{Acknowledgments}

P.V. and B.D. are senior Clinical Investigators of the Fund for Scientific Research Flanders (FWOVlaanderen). D.V. is a senior Clinical Investigator supported by the Clinical Research Fund of the University Hospitals Leuven, Belgium. This work was supported by a grant from the Fund for Scientific Research Flanders (FWO-Vlaanderen grant \#G085413N).

The authors report no conflicts of interest 


\section{References}

Annesley, T. M. (2003). Ion suppression in mass spectrometry. Clin Chem 49(7): 1041-1044.

Blair, I. A. (2010). Analysis of estrogens in serum and plasma from postmenopausal women: past present, and future. Steroids 75(4-5): 297-306.

Botelho, J. C., C. Shacklady, H. C. Cooper, S. S. Tai, K. Van Uytfanghe, L. M. Thienpont and H. W. Vesper (2013). Isotope-dilution liquid chromatography-tandem mass spectrometry candidate reference method for total testosterone in human serum. Clin Chem 59(2): 372-380.

Callewaert, F., S. Boonen and D. Vanderschueren (2010). Sex steroids and the male skeleton: a tale of two hormones. Trends Endocrinol Metab 21(2): 89-95.

CLSI (2004). Evaluation of precision performance of quantitative measurement methods; approved guidelinesecond edition. . Wayne (PA): CLSI.

CLSI (2007). Mass spectrometry in the clinical laboratory: general principles and guidance; approved guideline. . Wayne (PA): CLSI.

Fiers, T., B. Casetta, B. Bernaert, E. Vandersypt, M. Debock and J. M. Kaufman (2012). Development of a highly sensitive method for the quantification of estrone and estradiol in serum by liquid chromatography tandem mass spectrometry without derivatization. J Chromatogr B Analyt Technol Biomed Life Sci 893-894: 57-62.

Folkerd, E. J., J. M. Dixon, L. Renshaw, R. P. A'Hern and M. Dowsett (2012). Suppression of plasma estrogen levels by letrozole and anastrozole is related to body mass index in patients with breast cancer. $J$ Clin Oncol 30(24): 2977-2980.

Jaque, J., H. Macdonald, D. Brueggmann, S. Patel, C. Azen, N. Clarke and F. Stanczyk (2013). Deficiencies in immunoassay methods used to monitor serum Estradiol levels during aromatase inhibitor treatment in postmenopausal breast cancer patients. SpringerPlus 2(1): 5 .

Khosla, S., L. J. Melton, 3rd and B. L. Riggs (2002). Clinical review 144: Estrogen and the male skeleton. J Clin Endocrinol Metab 87(4): 1443-1450.

Kushnir, M. M., A. L. Rockwood, J. Bergquist, M. Varshavsky, W. L. Roberts, B. Yue, A. M. Bunker and A. W. Meikle (2008). High-sensitivity tandem mass spectrometry assay for serum estrone and estradiol. Am J Clin Pathol 129(4): 530-539.

Manjunath Swamy, J., N. Kamath, A. K. Radha Shekar, N. R. Srinivas and F. Kristjansson (2010). Sensitivity enhancement and matrix effect evaluation during summation of multiple transition pairs-case studies of clopidogrel and ramiprilat. Biomed Chromatogr 24(5): 528-534.

Mayo Clinic, from http://www.mayomedicallaboratories.com/test-catalog/Clinical+and+Interpretive/81816. Retrieved March 2013.

Middle, J. G. and J. W. Kane (2009). Oestradiol assays: fitness for purpose? Ann Clin Biochem 46(Pt 6): 441-456. Nelson, R. E., S. K. Grebe, O. K. DJ and R. J. Singh (2004). Liquid chromatography-tandem mass spectrometry assay for simultaneous measurement of estradiol and estrone in human plasma. Clin Chem 50(2): 373-384.

Passing, H. and Bablok (1983). A new biometrical procedure for testing the equality of measurements from two different analytical methods. Application of linear regression procedures for method comparison studies in clinical chemistry, Part I. J Clin Chem Clin Biochem 21(11): 709-720.

Pauwels, S., A. Lintermans, P. Neven, J. Verhaeghe, I. Jans, J. Billen, D. Vanderschueren and P. Vermeersch (2013). Need for estradiol assays with a lower functional sensitivity in clinical studies examining postmenopausal women treated with aromatase inhibitors. J Clin Oncol 31(4): 509.

Rannulu, N. S. and R. B. Cole (2012). Novel fragmentation pathways of anionic adducts of steroids formed by electrospray anion attachment involving regioselective attachment, regiospecific decompositions, chargeinduced pathways, and ion-dipole complex intermediates. J Am Soc Mass Spectrom 23(9): 1558-1568.

Ray, J. A., M. M. Kushnir, A. Bunker, A. L. Rockwood and A. W. Meikle (2012). Direct measurement of free estradiol in human serum by equilibrium dialysis-liquid chromatography-tandem mass spectrometry and reference intervals of free estradiol in women. Clin Chim Acta 413(11-12): 1008-1014.

Ronan, J. M. and B. McHugh (2013). A sensitive liquid chromatography/tandem mass spectrometry method for the determination of natural and synthetic steroid estrogens in seawater and marine biota, with a focus on proposed Water Framework Directive Environmental Quality Standards. Rapid Commun Mass Spectrom 27(7): 738-746.

Rosner, W., S. E. Hankinson, P. M. Sluss, H. W. Vesper and M. E. Wierman (2013). Challenges to the Measurement of Estradiol: An Endocrine Society Position Statement. J Clin Endocrinol Metab.

Shahinian, V. B., Y. F. Kuo, J. L. Freeman and J. S. Goodwin (2005). Risk of fracture after androgen deprivation for prostate cancer. N Engl J Med 352(2): 154-164. 
Sheen, J. F. and G. R. Her (2004). Analysis of neutral drugs in human plasma by fluoride attachment in liquid chromatography/negative ion electrospray tandem mass spectrometry. Rapid Commun Mass Spectrom 18(17): 1911-1918.

Stanczyk, F. Z., J. Jurow and A. W. Hsing (2010). Limitations of direct immunoassays for measuring circulating estradiol levels in postmenopausal women and men in epidemiologic studies. Cancer Epidemiol Biomarkers Prev 19(4): 903-906.

Tai, S. S. and M. J. Welch (2005). Development and evaluation of a reference measurement procedure for the determination of estradiol-17beta in human serum using isotope-dilution liquid chromatography-tandem mass spectrometry. Anal Chem 77(19): 6359-6363.

Xu, X., J. M. Roman, H. J. Issaq, L. K. Keefer, T. D. Veenstra and R. G. Ziegler (2007). Quantitative measurement of endogenous estrogens and estrogen metabolites in human serum by liquid chromatography-tandem mass spectrometry. Anal Chem 79(20): 7813-7821.

Yamashita, K., M. Okuyama, Y. Watanabe, S. Honma, S. Kobayashi and M. Numazawa (2007). Highly sensitive determination of estrone and estradiol in human serum by liquid chromatography-electrospray ionization tandem mass spectrometry. Steroids 72(11-12): 819-827.

Yang, W. C., F. E. Regnier, D. Sliva and J. Adamec (2008). Stable isotope-coded quaternization for comparative quantification of estrogen metabolites by high-performance liquid chromatography-electrospray ionization mass spectrometry. J Chromatogr B Analyt Technol Biomed Life Sci 870(2): 233-240. 
Tables

Table 1: MRM settings for E2, IS2, E1, and IS

\begin{tabular}{llllll}
\hline Compound & $\begin{array}{l}\text { Q1 Mass } \\
(\mathrm{Da})\end{array}$ & $\begin{array}{l}\text { Q3 Mass } \\
(\mathrm{Da})\end{array}$ & $\begin{array}{l}\text { CE } \\
(\text { Volt })\end{array}$ & $\begin{array}{l}\text { CXP } \\
\text { (Volt) }\end{array}$ & $\begin{array}{l}\text { Dwell time } \\
\text { (msec) }\end{array}$ \\
\hline E2 & 271.20 & 145.00 & -55 & -19 & 60 \\
E2 & 271.20 & 145.00 & -55 & -19 & 60 \\
E2 & 271.20 & 145.00 & -55 & -19 & 60 \\
E2 & 271.20 & 145.00 & -55 & -19 & 60 \\
E2 & 271.20 & 145.00 & -55 & -19 & 60 \\
IS2 & 274.20 & 145.00 & -55 & -19 & 60 \\
E1 & 269.20 & 145.00 & -48 & -8 & 60 \\
IS1 & 272.20 & 148.00 & -48 & -8 & 60 \\
& & & & &
\end{tabular}

CE: Collision Energy; CXP: Collision cell exit potential

Table 2 Total imprecision for E2 and E1 at low and high QC

\begin{tabular}{cccc}
\hline & & QC low & QC high \\
E2 & Average $\mathrm{ng} / \mathrm{L}(\mathbf{p m o l} / \mathrm{L})$ & $1.5(5.5)$ & $22.5(82.7)$ \\
& $\mathrm{CV}(\%)$ & 19.1 & 8.8 \\
E1 & Average $\mathrm{ng} / \mathrm{L}(\mathbf{p m o l} / \mathrm{L})$ & $3.5(13.0)$ & $32.0(118.5)$ \\
& $\mathrm{CV}(\%)$ & 10.6 & 5.8 \\
& & & \\
\hline
\end{tabular}

Table 3 Results for E2 and E1 in adult men ( $n=25)$ by MS and direct immunoassay and E2 and E1 in postmenopausal women ( $n=30)$ and postmenopausal women treated with Al $(n=15)$ by MS

\begin{tabular}{|c|c|c|c|c|c|c|c|c|}
\hline & \multicolumn{4}{|l|}{$\begin{array}{l}\text { Adult men } \\
(n=25)\end{array}$} & \multicolumn{2}{|c|}{$\begin{array}{l}\text { Postmenopausal Women } \\
(n=30)\end{array}$} & \multicolumn{2}{|l|}{$\begin{array}{l}\text { Al } \\
(n=15)\end{array}$} \\
\hline & $\begin{array}{l}\mathrm{E2} \text { (ng/L) } \\
\text { (pmol/L) }\end{array}$ & & $\begin{array}{l}\text { E1 (ng/L) } \\
\text { (pmol/L) }\end{array}$ & & $\begin{array}{l}\text { E2 (ng/L) } \\
\text { (pmol/L) }\end{array}$ & $\begin{array}{l}\text { E1 (ng/L) } \\
\text { (pmol/L) }\end{array}$ & $\begin{array}{l}\text { E2 (ng/L) } \\
\text { (pmol/L) }\end{array}$ & $\begin{array}{l}\text { E1 (ng/L) } \\
\text { (pmol/L) }\end{array}$ \\
\hline & MS & ECLIA & MS & RIA & MS & MS & MS & MS \\
\hline Median & $\begin{array}{l}16.6 \\
(61.0)\end{array}$ & $\begin{array}{l}18.7 \\
(68.7)\end{array}$ & $\begin{array}{l}20.5 \\
(75.9)\end{array}$ & $\begin{array}{l}56.2 \\
(208.2)\end{array}$ & $\begin{array}{l}3.2 \\
(11.8)\end{array}$ & $\begin{array}{l}18.2 \\
(67.4)\end{array}$ & $<\mathrm{LOQ}$ & $<\mathrm{LOQ}$ \\
\hline Range & $\begin{array}{l}8.7-32.0 \\
(32.0-117.6)\end{array}$ & $\begin{array}{l}5.7-33.8 \\
(20.9-124.2)\end{array}$ & $\begin{array}{l}9.0-60.5 \\
(33.3-224.1)\end{array}$ & $\begin{array}{l}16.7-85.2 \\
(61.9-315.6)\end{array}$ & $\begin{array}{l}<L O Q-9.5 \\
(<L O Q-34.9)\end{array}$ & $\begin{array}{l}7.0-41.8 \\
(25.9-154.8)\end{array}$ & All <LOQ & $\begin{array}{l}<\text { LOQ-1.6 } \\
(<\text { LOQ-5.9) }\end{array}$ \\
\hline Below LOQ & 0 & 0 & 0 & 0 & 5 & 0 & 15 & 14 \\
\hline$r^{2}$ & 0.64 & & 0.12 & & / & / & / & / \\
\hline
\end{tabular}




\section{Figures}

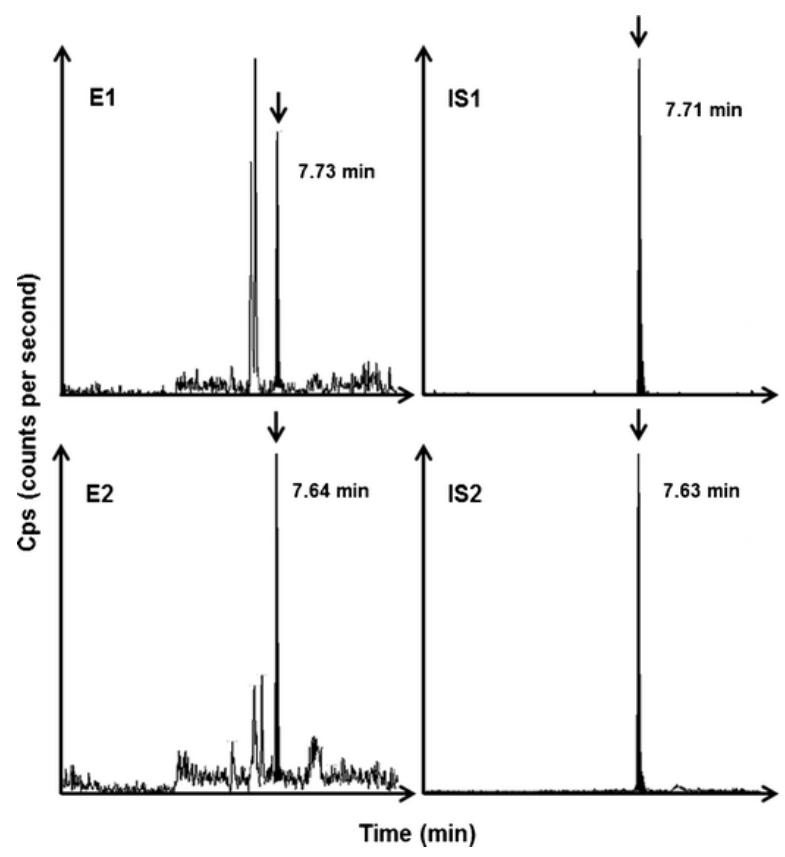

Figure 1 Chromatogram of E1 and IS1 in serum at $3.3 \mathrm{ng} / \mathrm{L}$ (12.2 pmol/L) and chromatogram of E2 and IS2 in serum at $4.0 \mathrm{ng} / \mathrm{L}(14.7 \mathrm{pmol} / \mathrm{L})$

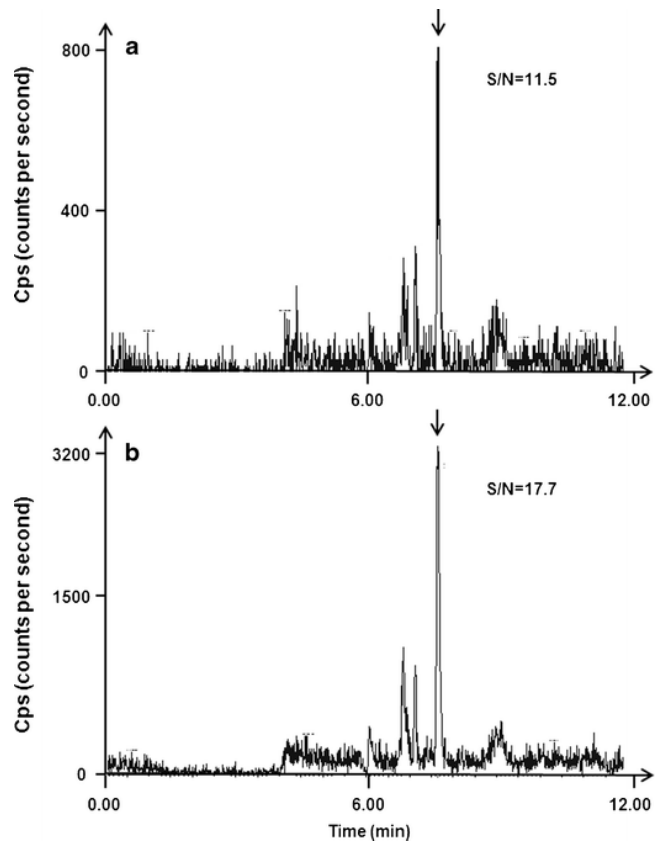

Figure 2 Chromatograms of E2 in serum with $S / N$ for one MRM (a) and for the summation of 5 identical MRMs (b)
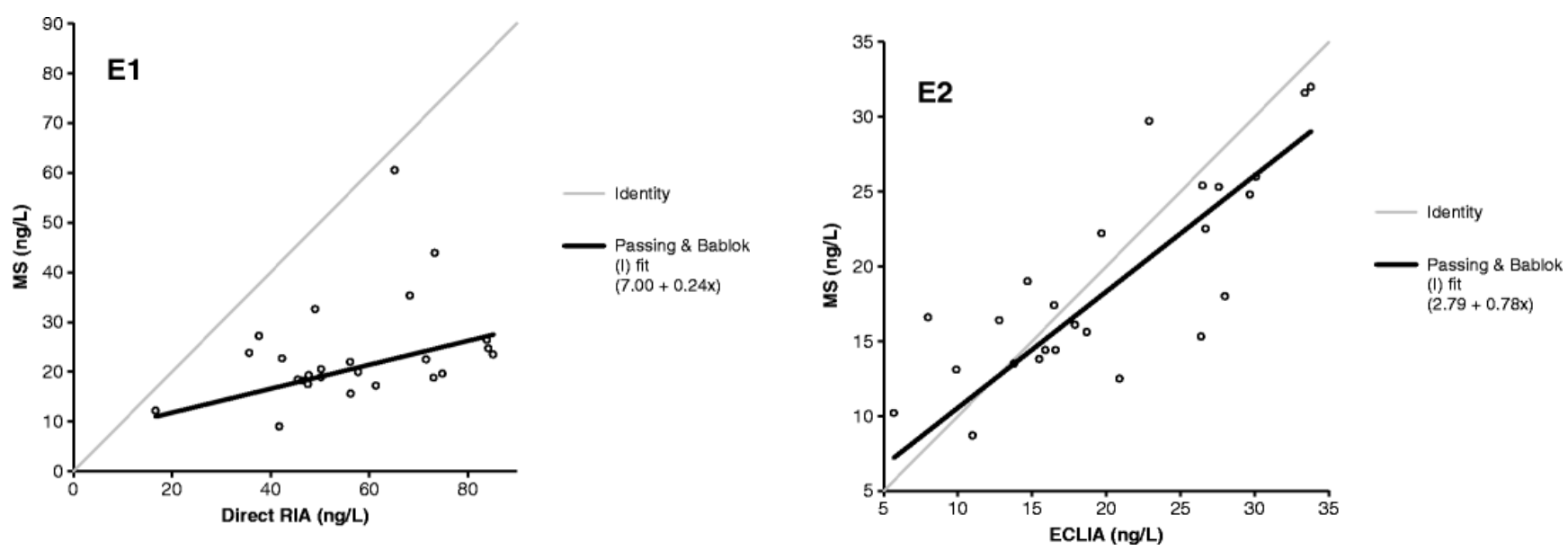

Figure 3 Passing-Bablok 90 regression for E1 and E2, Direct immunoassay (ECLIA/RIA) was selected as reference method ( $x$ )and MS as test method ( $y$ ) 


\section{Supplementary Material}

Supplementary Table 1: Gradient, flow and solvents

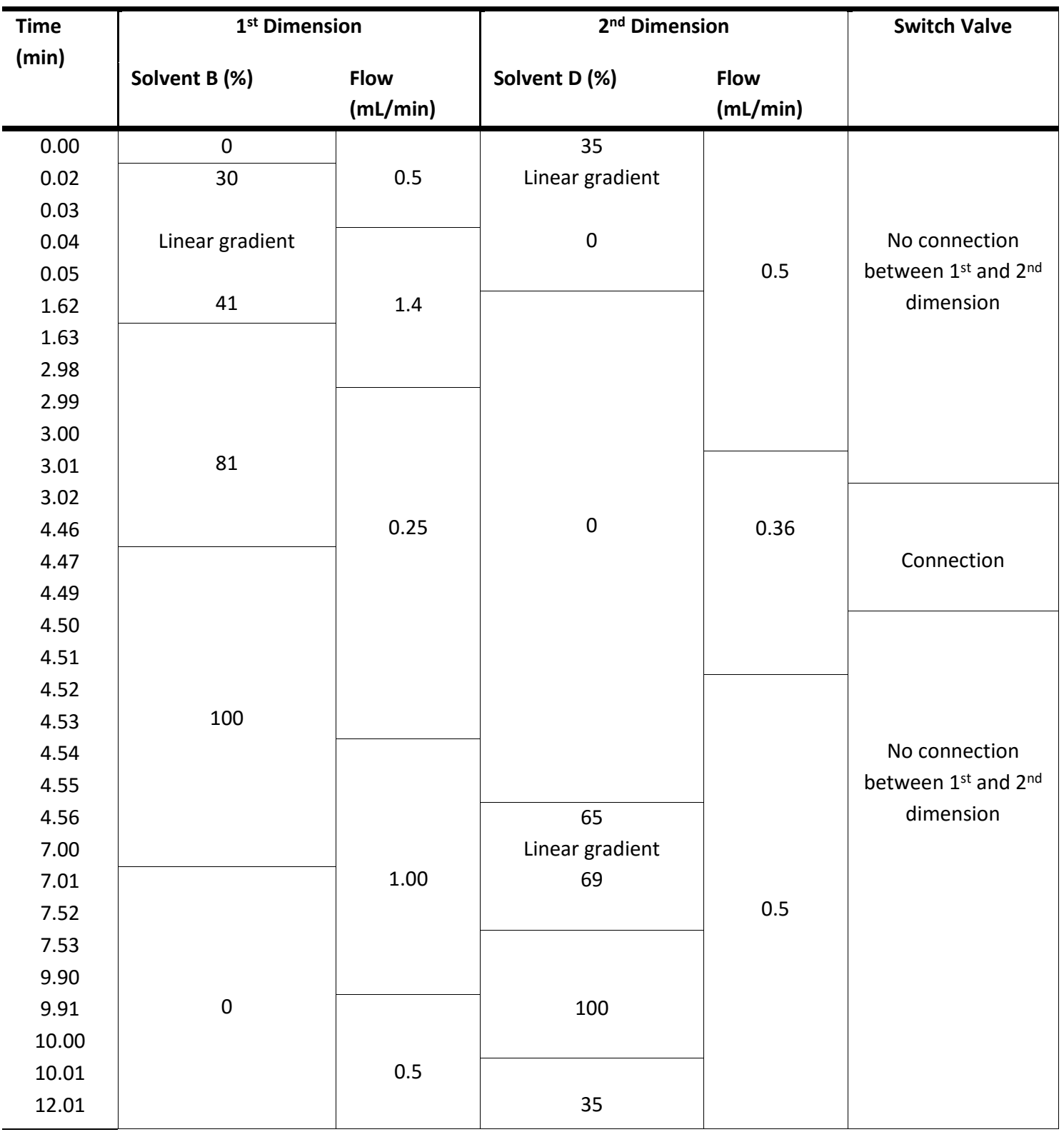

The first dimension is served by 2 pumps that provide a mixture of water (solvent $A$ ) and methanol/acetonitrile (75/25 v/v) (solvent $B$ ). The second dimension (analytical column) is served by 2 other pumps that provide a mixture of $0.4 \mathrm{mM}$ ammonium fluoride in water (solvent $C$ ) and methanol (solvent $D$ ) 
Supplementary Table 2 ME for E2 and E1 in calibration standard matrix and blank serum matrix

\begin{tabular}{cccc}
\hline Compound & $\begin{array}{c}\text { Concentration } \\
\text { ng/L (pmol/L) }\end{array}$ & $\begin{array}{c}\text { ME (\%) } \\
\text { spiked serum }\end{array}$ & $\begin{array}{c}\text { ME (\%) } \\
\text { calibration standard }\end{array}$ \\
& $1.3(4.8)$ & 100 & 120 \\
$2.7(9.9)$ & 106 & 108 \\
E2 & $5.4(19.9)$ & 85 & 104 \\
& $26.8(98.5)$ & 96 & 104 \\
& $53.5(196.7)$ & 105 & 100 \\
& & & 105 \\
& $1.2(4.4)$ & 87 & 108 \\
& $4.9(18.1)$ & 97 & 91 \\
& $39.2(145.2)$ & 100 & 104 \\
& $78.4(290.4)$ & 101 & 103 \\
& $156.8(580.8)$ & 97 & \\
\hline
\end{tabular}

Supplementary Table 3 Results for regression and correlation analysis

\begin{tabular}{|c|c|c|c|c|c|c|}
\hline \multirow[b]{2}{*}{ Regression } & \multicolumn{3}{|c|}{ ECLIA versus MS for E2 } & \multicolumn{3}{|c|}{ RIA versus MS for E1 } \\
\hline & $\begin{array}{c}\text { Slope } \\
\text { (Cl 95\%) }\end{array}$ & $\begin{array}{l}\text { Intercept } \\
\text { (Cl 95\%) }\end{array}$ & $r^{2}$ & $\begin{array}{c}\text { Slope } \\
\text { (Cl 95\%) }\end{array}$ & $\begin{array}{l}\text { Intercept } \\
\text { (Cl 95\%) }\end{array}$ & $\mathbf{r}^{2}$ \\
\hline Passing-Bablok & $\begin{array}{c}0.78 \\
(0.55-1.00)\end{array}$ & $\begin{array}{c}2.79 \\
(-1.80-7.68)\end{array}$ & / & $\begin{array}{c}0.24 \\
(0.13-0.53)\end{array}$ & $\begin{array}{c}7.00 \\
(-7.51-13.14)\end{array}$ & / \\
\hline Deming & $\begin{array}{c}0.78 \\
(0.57-1.00)\end{array}$ & $\begin{array}{c}3.25 \\
(-1.32-7.83)\end{array}$ & / & $\begin{array}{c}0.31 \\
(-0.05-0.67)\end{array}$ & $\begin{array}{c}5.87 \\
(-12.15-23.88)\end{array}$ & / \\
\hline Linear & $\begin{array}{c}0.66 \\
(0.45-0.87)\end{array}$ & $\begin{array}{c}5.75 \\
(1.19-10.31)\end{array}$ & 0.64 & $\begin{array}{c}0.21 \\
(-0.04-0.46)\end{array}$ & $\begin{array}{c}11.44 \\
(-3.37-26.25)\end{array}$ & 0.12 \\
\hline
\end{tabular}

RIA/ECLIA was selected as reference method $(x)$ and $M S$ as test method $(y)$

Supplementary Table 4 Baseline and post-castration values for all three tested men

\begin{tabular}{ccccc}
\hline & \multicolumn{2}{c}{ Baseline } & \multicolumn{2}{c}{ Chemically Castrated } \\
Patient & E2 ng/L (pmol/L) & E1 ng/L (pmol/L) & E2 ng/L (pmol/L) & E1 ng/L (pmol/L) \\
$\mathbf{1}$ & $19.8(72.8)$ & $19.4(71.9)$ & $3.8(14.0)$ & $6.4(23.7)$ \\
$\mathbf{2}$ & $39.8(146.3)$ & $55.0(203.7)$ & $5.5(20.2)$ & $23.9(88.5)$ \\
$\mathbf{3}$ & $26.2(96.3)$ & $33.4(123.7)$ & $<\mathrm{LOQ}$ & $7.2(26.7)$ \\
& & & & \\
\hline
\end{tabular}

Supplementary Table 5 Results for E2 measured by ECLIA and by MS for all 5 patients treated with exemestane

\begin{tabular}{ccc}
\hline Patient & E2 MS ng/L (pmol/L) & E2 ECLIA ng/L (pmol/L) \\
$\mathbf{1}$ & $<1.3(<4.8))$ & $21(77.2)$ \\
$\mathbf{2}$ & $<1.3(<4.8)$ & $7(25.7)$ \\
$\mathbf{3}$ & $<1.3(<4.8)$ & $12(44.1)$ \\
$\mathbf{4}$ & $<1.3(<4.8)$ & $33(121.3)$ \\
$\mathbf{5}$ & $<1.3(<4.8)$ & $15(55.1)$ \\
\hline
\end{tabular}

